\title{
Erratum to: "Anaerobic Methane Oxidation in Enrichment Cultures from Deep Sediments of a Mud Volcano Peschanka (South Baikal)" [Microbiology 87, 317 (2018)]
}

\author{
A. V. Lomakina ${ }^{a}{ }^{*}$, E. V. Mamaeva ${ }^{a}$, T. V. Pogodaeva ${ }^{a}$, G. V. Kalmychkov ${ }^{b}$, \\ I. A. Khal'zov ${ }^{a}$, and T. I. Zemskaya ${ }^{a}$ \\ ${ }^{a}$ Limnological Institute, Siberian Branch, Russian Academy of Sciences, Irkutsk, 664033 Russia \\ ${ }^{b}$ Vinogradov Institute of Geochemistry, Siberian Branch, Russian Academy of Sciences, Irkutsk, 664033 Russia \\ *e-mail: lomakina@lin.irk.ru \\ Submitted July 27, 2018
}

DOI: $10.1134 / \mathrm{S} 0026261718060139$

Throughout the text of the article, Fe(III) and Mn(IV) should read instead of Fe(II) and Mn(II). The original article can be found online at

$10.1134 / \mathrm{S} 0026261718030049$ 